\title{
Bir üniversite hastanesindeki sağlık personelinin el hijyeni uyum oranlarının değerlendirilmesi: Prospektif bir çalışma
}

\section{Evaluation of hygiene compliance rates among healthcare workers in} a university hospital: A prospective study

\begin{tabular}{|c|c|c|c|}
\hline Demet Dikiş ${ }^{1}$ & Sera Şimşek ${ }^{2}$ & Nurhayat Kepeli ${ }^{1}$ & Nilgün Deniz Küçükler ${ }^{1} \mathbb{D}$ \\
\hline Behiye Ulusoy ${ }^{1}$ & Nilay Bilgili Korkmaz ${ }^{1}$ & Şükran Akşit Barık ${ }^{1}$ (D) & Nilüfer Uzunbayır Akel ${ }^{1} \mathbb{D}$ \\
\hline Hüseyin Aytaç Erdem ${ }^{3} \mathbb{D}$ & Oğuz Reşat Sipahi ${ }^{3}$ & Bilgin $\operatorname{Arda}^{3}$ & Fatma Feriha Çilli $i^{4}$ \\
\hline Dilek Yeşim Metin ${ }^{4}$ & Mehmet Ali Özinel $^{4}(\mathbb{D}$ & Sercan Ulusoy ${ }^{3}$ (D) & \\
\hline
\end{tabular}

Öz

Amaç: Bu çalışmanın amacı, 2014 ve 2018 yılları arasında yoğun bakım ünitelerinde (YBÜ) sağlık çalışanlarının el hijyeni uyum oranını saptamaktır.

Gereç ve Yöntem: Bu araştırma yedi YBÜ'de (Çocuk Sağlığı ve Hastalıkları, Yenidoğan, İç Hastalıkları, Anestezi ve Reanimasyon, Göğüs Hastalıkları, Nöroloji ve Kalp Damar Cerrahisi) çalışan doktor, hemşire ve yardımcı sağlık personelinin el hijyeni uyumunu değerlendiren prospektif, gözlemsel bir çalışmadır. El hijyeni uyumu enfeksiyon kontrol hemşireleri tarafından Dünya Sağlık Örgütü (DSÖ) beş endikasyonuna göre Ocak 2014 ile Aralık 2018 arasında haberli gözlem şeklinde yapılmıştır. Ayrıca, yüksek ve düşük el hijyeni uyumluluğuna sahip bireylere kişisel geri bildirimler verilmiştir.

Bulgular: Toplam 24153 el hijyeni fırsat gözlemi (2014: 5695, 2015: 5307, 2016: 4563, 2017: 4821, 2018: 3767) yapıldı. Çalışmamızda 2014'ün ilk döneminde el hijyeni uyum oranı \%25,6 idi. Tüm çalışanların el hijyeni uyum oranı sırasıyla; 2014: \%32,0, 2015: \%55,7, 2016: \%61,0, 2017: \%55,6 ve 2018: \%68,1 olmuştur. Mesleklere göre; el hijyeni uyum oranları hemşirelerde $\% 37$ ile $\% 70$, yardımcı sağlık personelinde \%20 ile \%51, doktorlarda \%28 ile \%49 arasındaydı.

Sonuç: Hastanemizde el hijyeni kurallarına uyum, sürekli çabalarla nispeten zayıf seviyelerden ortalama seviyelere yükselmiştir. El hijyeni uyum oranlarını \% 70 'lerin üstüne çıkarmak için daha fazla destekleyici çalışmaya intiyaç vardır.

Anahtar Sözcükler: El hijyeni, enfeksiyon kontrolü, hastane epidemiyolojisi, hastane enfeksiyonları.

\section{Abstract}

Aim: The aim of this study was to determine the hand hygiene $(\mathrm{HH})$ compliance of the health workers in the intensive care units (ICUs) between the years 2014 and 2018.

Materials and Methods: A prospective, observational study assessed the hospital care $\mathrm{HH}$ compliance among doctors and nurses and auxiliary staff in seven ICUs (Pediatrics, Neonatal, Internal Medicine, Anesthesia and Reanimation, Chest Diseases, Neurology and Cardiovascular Surgery) of our setting.

\footnotetext{
Sorumlu yazar: Sera Simsek

Ege Üniversitesi Tıp Fakültesi, Halk Sağlığı Anabilim Dalı,

İmir, Türkiye

E-posta: seras-29@hotmail.com

Başvuru tarihi: 26.06.2019 Kabul tarihi: 26.12.2019
} 
Unblinded observations were conducted by infection control nurses between January 2014 and December 2018 according to the five indications based on World Health Organization (WHO) guidelines. Practical HH training was continued during the HH observations of employees at ICUs in our hospital. In addition, personal feedback was given to individuals with high and low HH compliance.

Results: A total of 24153 HH opportunity (2014: 5695, 2015: 5307, 2016: 4563, 2017: 4821, 2018: 3767) observations were made. In the first period of 2014, the rate of HH compliance was $25.6 \%$. The HH compliance rates of all employees were as follows: 2014: 34\%, 2015: 55.7\%, 2016: 61.0\%, 2017: 55.6\% and 2018: 68.1\%. According to occupations; HH compliance rates were found to range between $37 \%$ and $70 \%$ in nurses, $20 \%$ and $51 \%$ in auxiliary healthcare personnel, $28 \%$ and $49 \%$ in doctors.

Conclusion: In our hospital compliance with $\mathrm{HH}$ rules increased from relatively poor levels to relatively average levels via continuous efforts. Further supportive studies are needed to increase $\mathrm{HH}$ compliance rates above $70 \%$.

Keywords: Hand hygiene, infection control, hospital epidemiology, nosocomial infections.

\section{Giriş}

El yıkama özellikle sağlık hizmeti ilişki enfeksiyonlar (SHIE) ile yakından ilişkilidir. İlk olarak Semmelweis tarafından yapılan el yıkama müdahalesi, kontamine olmuş ellerin düz sabun ve su ile yıkanmasındansa antiseptik bir ajanla temizlenmesinin SHIE bulaşını daha etkili bir şekilde azaltabileceğini göstermiştir (1). Daha sonraları Louis Pasteur ve Joseph Lister'in çalışmaları da bu verileri destekleyen nitelikte olmuştur. El hijyeni ile ilgili ilk rehber 1975 yılında Centers for Disease Control and Prevention (CDC) tarafından oluşturulmuş; sonraki yıllarda el yıkama rehberleri revize edilmiştir. İlk oluşturulan rehberlerde medikal olmayan su ve sabunla yapılan el yıkama daha ön planda iken, son yayımlanan rehberde özellikle görünür kirlenmenin olmadığı kontaminasyonlar için alkol bazlı el dezenfektanlarının kullanımı ilk önerilen uygulama olmuştur (1).

İnkübasyon döneminde olmayan veya enfeksiyon belirti ve bulguları göstermeyen kişilerde hastaneye yattıktan sonra 48-72 saat içinde, taburcu olduktan 10 gün sonra, ameliyat geçirenlerde bir ay içinde ve protez uygulananlarda bir yıl içinde gelişen enfeksiyonlar hastane enfeksiyonları olarak sınıflandırılır. CDC'ye göre 'yataklı tedavi kurumlarında, sağlık hizmetleri ile ilişkili olarak gelişen tüm enfeksiyonlar" hastane enfeksiyonu olarak adlandırılır. Hastane enfeksiyonları etkilenen hastalarda morbidite ve mortalitenin ana nedenleri arasındadır. Buna ek olarak hastane kaynaklı enfeksiyonlar, hastanede kalış süresinde uzamaya, tıbbi tedavilerde başarısızlığa, yaşam kalitesinde düşüşe ve tedavi maliyetlerinde artışa neden olur (2). Çoğunlukla da dirençli bakterilere bağı olarak gelişirler (3).

Yapılan çalışmalarda hastane enfeksiyonlarının yaklaşık \%65-70 oranında önlenebilir sebeplere bağlı oluştuğu bulunmuştur (4). Hastane florasında genellikle, metisiline dirençli stafilokoklar ve çoğul dirençli gram-negatif enterik çomaklar bulunmakta olup, hastane içerisinde yüksek virülans ve çoklu ilaç direnci gösteren mikroorganizmaların hastalar arasında taşınması ve yayılmasında kaynak yaklaşık \%40 oranında sağlık çalışanlarının kirli elleridir $(5,6)$. El hijyeni, Dünya Sağlık Örgütü (DSÖ) El Hijyeni Kılavuzu'nda 'El temizliğinin herhangi bir eylemine atıfta bulunan genel bir terim" olarak tanımlanmış, sabun/antiseptik ve su ile el yıkama, alkol ile el ovma olarak belirlenmiştir (7). Sağlık hizmeti ile ilişkili enfeksiyonları önlemede en önemli faktörlerden birinin el hijyenine uyum olduğu görülmüştür. El temizliğinin "yeterince ve doğru" uygulanması ile hastane enfeksiyonlarının en azından bir kısmının kontrolü sağlanabilmektedir. Dünya Sağlık Örgütü'nün 2012 raporunda, YBÜ'lerde enfeksiyonların çoğu (\%51'e varan oranda) hastane enfeksiyonu olarak tanımlanmıştır. Özellikle YBÜ'lerde aktif bir role sahip olan yardımcı sağlık personeline yeterli sıklıkta el yıkama alışkanlığının kazandırılması, SHIE önlenmesi için son derece önemlidir (5). Bu çalışmada 2014-2018 yılları arasında hastanemiz YBÜ'lerde görev yapan sağlık çalışanlarının el hijyeni uyum oranlarının değerlendirilmesi amaçlanmıştır.

\section{Gereç ve Yöntem}

$\mathrm{Bu}$ çalışmada sunulan el hijyeni verileri, hastanemizde prospektif olarak toplandı ve 
retrospektif olarak değerlendirildi. Çocuk Sağlığı ve Hastalıkları, Yenidoğan, İç Hastalıkları, Anestezi ve Reanimasyon, Göğüs Hastalıkları, Nöroloji ve Kalp Damar Cerrahisi YBÜ'lerinde görev yapan tüm sağlık çalışanlarına 2014-2018 yılları arasında el hijyeni gözlemleri yapıldı. Bağımlı değişken, el hijyenine uyumdu. Veriler DSÖ 'El Hijyeni 5 Endikasyon Kuralı' çerçevesinde hazırlanan el hijyeni gözlem formu ile enfeksiyon kontrol komitesi hemşireleri tarafından toplandı. Bu formda hasta ile temas öncesi, aseptik işlemler öncesi, vücut sıvılarının bulaşma riski sonrası, hasta ile temas sonrası ve hasta çevresi ile temas sonrası olmak üzere beş bölüm mevcuttu. Bu beş bölümde fırsat, el yıkama ve el ovma gözlemlenerek değerlendirildi. Fırsat gözlemleri, enfeksiyon kontrol komitesi hemşireleri tarafından YBÜ'lerde görev alan sağlık çalışanlarına haberli bir şekilde hastaya yapılan tıbbi işlemlerde beş endikasyona göre el yıkama ve el ovma davranışının gözlemlenmesi ile gerçekleştirildi. Bağımsız değişkenler: yıl, meslek ve cinsiyet olarak belirlendi. Veriler Excel programı kullanılarak analiz edildi. Her endikasyonda fırsat gözlemi, el yıkama ve el ovma davranışı için 0 ve 1 puanlaması yapıldı. El hijyenine uyum oranı, el yıkama ve el ovma puanlarının toplanıp fırsat puanına bölünmesi ve 100 ile çarpılması ile elde edildi.

Çalışma süresince EÜTF YBÜ'de görev yapan sağlık çalışanlarının el hijyenleri gözlemleri sırasında uygulamalı el hijyeni eğitimlerine devam edildi. Geribildirimlerin çalışanları motive etmesi için, el hijyeni uyum sonuçları tüm personele okutulup imzalatılmak üzere anabilim dalı başkanlarına üçer aylık periyotlar halinde bildirildi. Bunun yanında kişiye özel geribildirim olarak el hijyeni uyumu yüksek olan (>\%70) kişilere teşekkür, uyumu düşük olanlara $(<\% 30)$ ise uyarı yazıları gönderildi.

\section{Bulgular}

Çalışma periyodunda toplam 24153 el hijyeni fırsatı (2014: 5695, 2015: 5307, 2016: 4563, 2017: 4821, 2018: 3767) gözlemi yapıldı. Fırsat gözlemleri sonucunda el ovma davranışının yıllara göre arttığı görüldü. El ovma oranları 2014 ile 2017 yılları arasında \%11,0 ile \%35,0 aralığında değişmekteydi. El yıkama davranışı ise yıllar içerisinde değişkenlik göstermiş olup, $\% 20,6$ ile \%26,0 aralığındaydı (Tablo-1). Çalışmanın 2018 yılına ait verileri bakanlık sistemine girildiğinden el yıkama ve el ovma ayrımı yapılmadı.

Hastanemiz YBÜ'lerindeki sağlık çalışanlarının mesleklerine göre el hijyeni uyum oranları Tablo2'de sunulmuştur. El hijyeni uyum oranının en az görüldüğü grup doktorlar iken, en fazla görüldüğü grup hemşireler olmuştur. Cinsiyetler arası değerlendirme sonucu kadınlarda uyum erkeklere göre daha yüksek saptandı. Her iki cinsiyette de yıllara göre artan bir uyum mevcuttu (Tablo-3). 2016-2018 yılında toplamda 85 teşekkür 60 uyarı yazısı gönderildi.

Tablo-1. Yıllara göre el yıkama ve el ovma davranışlarına uyum yüzdeleri.

\begin{tabular}{ccccc}
\hline YIL & $\begin{array}{c}\text { Firsat } \\
\text { N }\end{array}$ & $\begin{array}{c}\text { El yıkama } \\
\%\end{array}$ & $\begin{array}{c}\text { El ovma } \\
\%\end{array}$ & $\begin{array}{c}\text { El hijyeni } \\
\text { yok } \\
\%\end{array}$ \\
\hline 2014 & 5695 & 21,0 & 11,0 & 68,0 \\
2015 & 5307 & 23,5 & 32,2 & 44,3 \\
2016 & 4563 & 26,0 & 35,0 & 39,0 \\
2017 & 4821 & 20,6 & 35,0 & 44,4 \\
2018 & 3767 & - & - & 31,9 \\
\hline
\end{tabular}

Tablo-2. El hijyenine uyumun yıllara ve mesleklere göre dağılımı.

\begin{tabular}{ccccc}
\hline YIL & $\begin{array}{c}\text { Doktor } \\
\%\end{array}$ & $\begin{array}{c}\text { Hemşire } \\
\%\end{array}$ & $\begin{array}{c}\text { Personel } \\
\%\end{array}$ & $\begin{array}{c}\text { Toplam } \\
\%\end{array}$ \\
\hline 2014 & 28,0 & 37,0 & 20,0 & 32,0 \\
2015 & 41,5 & 61,8 & 51,7 & 55,7 \\
2016 & 48,6 & 70,0 & 49,0 & 61,0 \\
2017 & 46,0 & 61,6 & 51,0 & 55,6 \\
2018 & 61,2 & 71,2 & 68,2 & 68,1 \\
\hline
\end{tabular}

Tablo-3. El hijyenine uyumun cinsiyete ve yıllara göre dağılımı.

\begin{tabular}{lccccc}
\hline CINSIYET & $\begin{array}{c}2014 \\
\%\end{array}$ & $\begin{array}{c}2015 \\
\%\end{array}$ & $\begin{array}{c}2016 \\
\%\end{array}$ & $\begin{array}{c}2017 \\
\%\end{array}$ & $\begin{array}{c}2018 \\
\%\end{array}$ \\
\hline Kadın & 37,1 & 59,8 & 66,0 & 62,3 & 71,6 \\
Erkek & 22,5 & 44,2 & 50,0 & 43,1 & 60,4 \\
\hline
\end{tabular}

\section{Tartışma}

El yıkama hastane enfeksiyonlarını önlemede en önemli ve en kolay uygulanabilir standart önlemlerden biridir. Buna rağmen sağlık 
çalışanlarında el hijyenine uyumun yetersiz olduğu bilinmektedir. Yapılan çalışmalarda bu uyum genellikle \%40-50 arasında saptanmaktadır (8). Bizim sonuçlarımız 2014'te görece daha kötü, 2018'de ise görece daha iyi durumdaydı. Enfeksiyon kontrol komitesi olarak el hijyeni uyum oranlarının \%70'lerin üstüne çıkarılması hedeflenmektedir. Komitemizin hedefi olarak da bu hedefin ötesinde ideal oranı \%100 kabul etsek de uyum oranımız henüz istenilen noktada değildir. Hastanemizdeki altyapı sorunları, personel eksikliği, hasta yoğunluğu, eğitim eksikliği gibi nedenler el hijyenine uyumdaki noksanlığın sebebi olabileceği gibi, sağlık çalışanlarının el hijyeni kurallarını yeterince benimsememiş olmaları da bir neden olabilir $(6$, $9,10)$.

Çalışmamızda el hijyenine uyum oranı son derece düşük olarak saptanmış olup yıllar geçtikçe bu uyumun arttığı görülmüştür. Periyodik izlem ve anabilim dallarına yapılan geri bildirimlerin el temizliği kurallarına uyumun artırımasında önemli katkılar sağladığı düşünülmektedir (11). Gözlem yapılan sağlık çalışanları arasında el hijyenine uyumun en düşük olduğu grubu doktorlar oluşturmaktadır. Ege Üniversitesi Hastanesi YBÜ'lerinde 2005 yılında yapılan bir çalışma, el yıkama performansını doktorlarda en düşük olarak bulmuştur (6). Hastane genelinde uyumun en düşük olduğu 2014 yılında \%28,0, en yüksek olduğu 2018 yılında ise $\% 68,1$ 'lik uyum oranı vardı. Bu oranların gözlenen dört yıl boyunca \%50'den düşük olması doktorların iş yoğunluğu ile ilişkili olabilir $(11,12)$. El yıkama ile ilgili yapılan pek çok araştırmada el yıkama oranları farklı bulunsa da tüm çalışmalarda ortak nokta hekimler başta olmak üzere tüm sağlık çalışanlarının el hijyeni uyumlarının düşük düzeyde olduğudur $(8,13)$.

Çalışmamızda hemşirelerde el hijyeni uyumu doktorlara ve diğer sağlık personeline göre daha yüksekti. Ankara'da yapılan bir çalışmada hemşirelerin uyum oranı $\% 75,0$ bulunmuş olup bizim sonuçlarımız ile benzerdir (11). Avustralya'da sağlık çalışanlarında yapılan çalışmada da hemşirelerin uyum oranının diğer sağlık çalışanlarına kıyasla daha yüksek olduğuna dair destekleyici bulgular mevcuttur $(14,15)$. Yapılan pek çok diğer çalışmada da hemşirelerin el yıkama ve el hijyeni davranışlarının diğer sağlık çalışanlarına göre daha yüksek olduğu bildirilmiştir $(16,17)$. Kadınların erkeklere göre yüksek uyum oranlarına sahip olması ve hemşirelerin daha çok kadın cinsiyette olması bu sonuçlar ile ilişsili olabilir.

El yıkama oranları 2014-2018 yılları arasında belirgin değişiklik göstermezken, sağlık çalışanlarında el ovma oranı artmış, el hijyeni olmayanların oranı ise azalmıştır. El ovma oranı 2014'te \%11,0 iken 2017'de \%35,0'a çıkmıştır. Bu durum el ovma davranışının zaman içerisinde daha çok benimsendiğini göstermiştir. Tayvan'da yapılan bir müdahale araştırmasında alkol bazlı el ovmanın eğitim müdahalesinden sonra el yıkamaya göre daha çok benimsendiğini göstermiştir (13). Hindistan'da yapılan bir çalışmada ise alkol bazlı el antiseptiklerinin el hijyenine dahil olması ile uyum oranının arttığı bildirilmiştir (18). Yine aynı çalışmada el ovmanın, hızlı kuruması ve lavabo gerektirmemesi gibi nedenlerle hızlı bir uygulama olmasının uyumu artırdığı gösterilmiştir (18). Hastanede alkol bazlı el ovmanın erişilebilir ve etkili bir seçenek olarak sunulması el hijyenine uyumu artıracağı düşünülmektedir (10). Türkiye genelinde yapılan bir çalışma özellikle üçüncü basamak YBÜ'lerde sağlık çalışanlarının işgücünün yetersiz olduğunu göstermektedir (19). İş yükü fazlalığı, zaman darlığı, lavabolara ulaşamama ve sıcak suyun olmaması gibi sorunlar hastanemizde el yıkama davranışının düşüklüğünün sebebi olabilir (20).

Çalışmamızda bazı sınırlılıklar mevcuttur. Doğrudan gözlem, el hijyeninin değerlendirmesi için standart yöntem olarak kabul edilmektedir. Ancak, bu yöntem zahmetlidir ve gözlemci yanlılığına bağlıdır. Sunduğumuz çalışmada gözlemlenen katılımcılar gözlemlerin amacını biliyordu. $\mathrm{Bu}$ da el hijyeni uygulamalarını etkilemiş ve buna bağlı olarak gözlemlenenlerin uyum oranı gerçekte olduğundan daha yüksek bulunmuş olabilir. Buna bağlı olarak ilgili YBÜ'lerde kör gözlem yapılamamış olması başka bir dezavantajdır. El hijyeni oranlarıyla hastane enfeksiyon hızları korelasyonu yapılamamıştır. Bununla birlikte tek merkez verisi olarak gözlem sayısı oldukça yüksek bir veri setidir.

\section{Sonuç}

El hijyeni (el yıkama, el ovma) hastane enfeksiyonu hızlarının azaltılmasında en önemli ve etkili yöntemlerdendir. Bu konuda gerekli 
önemin yeterli düzeyde gösterilmesi enfeksiyon hızlarının azaltımasına önemli katkıda bulunacaktır. Enfeksiyon kontrol komitesi olarak el hijyeni uyum oranlarının \%70'lerin üstüne çıkarılması hedeflenmektedir. Hastane enfeksiyonlarının prevalansının azaltılması için el hijyenine uyumun artırılması ve gözlenenlerin gözlendiklerini bilmediği durumlarda el hijyeninin durumu hakkında destekleyici çalışmalara gerek vardır.

Çıkar çatışması: Yazarlar çıkar çatışması beyan etmemişlerdir.

\section{Kaynaklar}

1. Boyce JM, Pittet D. Guideline for Hand Hygiene in Health-Care Settings: Recommendations of the Healthcare Infection Control Practices Advisory Committee and the HICPAC/SHEA/APIC/IDSA Hand Hygiene Task Force. Infect Control Hosp Epidemiol. 2002; 23 (S12): S3-40.

2. Khan HA, Baig FK, Mehboob R. Nosocomial infections: Epidemiology, prevention, control and surveillance. Asian Pac J Trop Biomed. 2017; 7 (5): 478-82.

3. WHO Gözlemciler İçin Rehber. Geneva; 2007 [cited 2019 May 17]. Available from: https://dosyamerkez.saglik.gov.tr/Eklenti/4223,9dsorehberpdf.pdf?0

4. Umscheid CA, Mitchell MD, Doshi JA, Agarwal R, Williams K, Brennan PJ. Estimating the Proportion of Healthcare-Associated Infections That Are Reasonably Preventable and the Related Mortality and Costs. Infect Control Hosp Epidemiol. 2011; 32 (2): 101-14.

5. Artan Y, Sözeri İ, Durmaz Akyol A. Yoğun Bakımda Çalışan Yardımcı Hizmet Personelinin El Hijyeni Uyumunun Değerlendirilmesi. Yoğun Bakım Hemşireliği Derg. 2018; 22 (1): 10-8.

6. Arda B, Şenol Ş, Taşbakan MI, Yamazhan T, Sipahi OR, Arsu G, et al. Ege Üniversitesi Tıp Fakültesi Yoğun Bakım Ünitelerinde El Temizliği Kurallarına Uyumun Değerlendirilmesi. Yoğun Bakım Derg. 2005 [cited 2019 May 17]; 5 (3): 182-6.

7. WHO Guidelines on Hand Hygiene in Health Care First Global Patient Safety Challenge Clean Care is Safer Care. Geneva; 2009 [cited 2019 May 17]. Available from: https://apps.who.int/iris/bitstream/handle/10665/44102/9789241597906 eng.pdf;jsessionid=55D7E677A7D37 C74FC602B784D9C6FFF?sequence $=1$

8. Güçlü E, Tuna N, Yahyaoğlu M, Utku AÇ, Özcan Ö, Ceylan S, et al. Eğitimin ve Alkol Bazlı El Antiseptiklerinin Hastanede Yaygınlaştırılmasının El Hijyeni Uyumuna Etkisi. Flora. 2012; 17 (2): 118-25.

9. Awoke N, Geda B, Arba A, Tekalign T, Paulos K. Nurses Practice of Hand Hygiene in Hiwot Fana Specialized University Hospital, Harari Regional State, Eastern Ethiopia: Observational Study. Nurs Res Pract. 2018: 2654947

10. Yawson AE, Hesse AAJ. Hand Hygiene Practices And Resources İn A Teaching Hospital İn Ghana. J Infect Dev Ctries. 2013 Apr 17; 7 (04): 338-47.

11. Sönmezer MÇ, Gülhan B, Otuzoğlu M, Yakut Hí, Tezer H. Evaluation of Hand Hygiene Compliance of Health Personnel in the Pediatric Intensive Care Unit. Turkish J Pediatr Dis. 2014 Jun 20; 8 (2): 75-8.

12. Demirdal T, Uyar S, Demirtürk N. Bir Üniversite Hastanesinde Çalışanlarda El Yıkama Uygulamalarının ve Bilgi Düzeylerinin Değerlendirmesi. Med J Kocatepe. 2007;8 (3): 39-43.

13. Lai C-C, Lu M-C, Tang H-J, Chen Y-H, Wu Y-H, Chiang H-T, et al. Implementation Of A National Quality İmprovement Program To Enhance Hand Hygiene İn Nursing Homes İ Taiwan. J Microbiol Immunol Infect. 2019 Apr 1 [cited 2019 May 17]; 52 (2): 345-51.

14. Grayson ML, Stewardson AJ, Russo PL, Ryan KE, Olsen KL, Havers SM, et al. Effects Of The Australian National Hand Hygiene Initiative After 8 Years On İnfection Control Practices, Health-Care Worker Education, And Clinical Outcomes: A Longitudinal Study. Lancet Infect Dis. 2018 Nov 1 [cited 2019 May 17]; 18 (11): 1269-77.

15. Uyan A, Aksoy F, Azak E, Meriç Koç M, Alkan Çeviker S, Ataman Hatipoğlu Ç, et al. Hand Hygiene Compliance in Some Intensive Care Units of Turkey: Results of Multicentre Asklepeion Study. Mediterr $J$ Infect Microb Antimicrob 2018;7:37 doi: 10.4274/mjima.2018.37

16. Farhoudi F, Sanaei Dashti A, Hoshangi Davani M, Ghalebi N, Sajadi G, Taghizadeh R. Impact of WHO Hand Hygiene Improvement Program Implementation: A Quasi-Experimental Trial. Biomed Res Int. 2016 [cited 2019 May 17]; 2016: 7026169. 
17. Alshammari M, Reynolds K, Verhougstraete M, O'Rourke M. Comparison of Perceived and Observed Hand Hygiene Compliance in Healthcare Workers in MERS-CoV Endemic Regions. Healthcare. 2018 Oct 7 [cited 2019 May 17]; 6 (4): 122.

18. Biswas A, Bhattacharya S Das, Singh AK, Saha M. Addressing Hand Hygiene Compliance in a LowResource Neonatal Intensive Care Unit: a Quality Improvement Project. J Pediatric Infect Dis Soc. J Pediatric Infect Dis Soc. 2018 Sep 4. doi: 10.1093/jpids/piy076

19. Uyan A, Durmuş G, Sezak N, Pepe F, Kaygusuz T, Öztoprak N, et al. Is Nurse Workforce Sufficient in Intensive Care Units in Turkey? Results of the Multicenter Karia Study. Mediterr J Infect Microb Antimicrob. 2017; 6: 20.

20. Uyan A, Durmuş G, Sezak N, Özdemir B, Kaygusuz T, Öztoprak N, et al. Are Soap, Paper Towel and Alcohol-based Disinfectants Easily Accessible in Intensive Care Units in Turkey?: Results of the Phokai Study. Mediterr J Infect Microbes Antimicrob. 2019 doi: 10.4274/mjima.2018.20. 